\title{
Acute respiratory distress syndrome secondary to antisynthetase syndrome is reversible with tacrolimus
}

\author{
S. Guglielmi*, T.M. Merz ${ }^{\#}$, M. Gugger ${ }^{\top}$, C. Suter* and L.P. Nicod*
}

ABSTRACT: Polymyositis and interstitial lung diseases, predominantly nonspecific interstitial pneumonia (NSIP), are known to be frequent in antisynthetase syndrome, where anti-aminoacyltRNA synthetase antibodies are often identified.

An unusual case of acute respiratory distress syndrome, secondary to such proven NSIP of cellular type with predominant CD8 lymphocytes, is described herein.

The patient described in the present case study initially had a poor recovery with high dose of steroids, but this was followed by a good improvement after the prescription of tacrolimus and a low dose of prednisone.

A precise diagnosis in similar circumstances may be life-saving, allowing the successful application of new immunosuppressants.

KEYWORDS: Antisynthetase syndrome, dermatomyositis, interstitial lung diseases, interstitial pulmonary fibrosis, nonspecific interstitial pneumonia, polymyositis

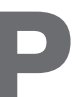

olymyositis (PM) and dermatomyositis (DM) are systemic inflammatory diseases that may, besides the muscles, affect different organ systems. If the pulmonary system is involved, severe interstitial lung diseases can result $[1,2]$. The prognosis of such patients is dependent on the severity of the lung disease [3]. As corticosteroid therapy is often insufficient, the use of efficacious immunosuppressant agents, particularly cyclosporine or tacrolimus, is needed, as recently shown [4, 5]. A case of nonspecific interstitial pneumonia (NSIP) with acute respiratory failure is described herein; the patient recovered with steroids and calcineurin inhibitors.

\section{CASE REPORT}

The present authors report herein the case of a 52yr-old male patient, who was hospitalised in the Emergency Dept at the Bern University Hospital (Bern, Switzerland) for respiratory failure. Before admission, the patient had suffered for several weeks from a productive cough, chest pains and a low-grade fever. Radiography showed bilateral pulmonary infiltrates. The patient acknowledged being a smoker and regularly drinking low doses of alcohol. While hospitalised in Libya, he had been treated first with ceftriaxon and erythromycin.
Additionally, as an infection with mycobacterium tuberculosis had been suspected, a treatment consisting of isoniazid, rifampicin and ethambutol had been applied a few days later for 2 weeks. During the last $48 \mathrm{~h}$ before admission to the present authors' hospital, the condition of the patient had deteriorated as he had developed a rapidly progressive respiratory insufficiency.

On admission to the Emergency Dept, the patient showed a severe, partial respiratory insufficiency with an arterial oxygen tension $\left(\mathrm{Pa}_{2} \mathrm{O}_{2}\right)$ of $7.3 \mathrm{kPa}$ under $8 \mathrm{~L}$ of oxygen. The patient was in reduced general condition, fulfilling the criteria for a systemic inflammatory response syndrome. Vital signs were as follows: blood pressure 124/ $49 \mathrm{mmHg}$; cardiac frequency 118 beats $\cdot \mathrm{min}^{-1}$; core temperature $37.5^{\circ} \mathrm{C}$; and respiratory frequency 30 beats $\cdot \mathrm{min}^{-1}$. The laboratory results showed an increased creatinine kinase of $940 \mathrm{U} \cdot \mathrm{L}^{-1} \quad\left(<190 \mathrm{U} \cdot \mathrm{L}^{-1}\right)$ and increased liver enzymes (aspartate aminotransferase $167 \mathrm{U} \cdot \mathrm{L}^{-1}$, alcaline phosphatase $132 \mathrm{U} \cdot \mathrm{L}^{-1}$ and $\gamma$-glutamyl transferase $\left.123 \mathrm{U} \cdot \mathrm{L}^{-1}\right)$. Furthermore, C-reactive protein was increased to $273 \mathrm{mg} \cdot \mathrm{L}^{-1}\left(<4 \mathrm{mg} \cdot \mathrm{L}^{-1}\right)$. The laboratory evaluation showed a haemoglobin value of $160 \mathrm{~g} \cdot \mathrm{L}^{-1}\left(125-168 \mathrm{~g} \cdot \mathrm{L}^{-1}\right)$, with normal
AFFILIATIONS

${ }^{*}$ Clinic and Policlinic for Pneumology,

"Dept of Intensive Care Medicine, Inselspital, and "Institute of Pathology, Bern University Hospital, Bern, Switzerland.

CORRESPONDENCE

L.P. Nicod

Clinic and Policlinic for Pneumology Bern University Hospital

CH-3010 Bern

Switzerland

Fax: 41316329833

E-mail: laurent.nicod@insel.ch

Received:

February 062007

Accepted after revision:

June 282007

STATEMENT OF INTERST

None declared. 
red blood cell indices. The white blood cell count was 13,200 leukocytes $\mu \mathrm{L}^{-1}\left(3,400-10,500\right.$ leukocytes $\left.\cdot \mu \mathrm{L}^{-1}\right)$, without left shift. High-resolution computed tomography (HRCT) of the lungs revealed diffuse acinar infiltrates, more confluent in both lower lobes, small bilateral pleural effusions and several small mediastinal lymph nodes (fig. 1c and d).

Due to his respiratory insufficiency, the patient was admitted to the intensive care unit. Antisynthetase syndrome was suspected due to initial presentation with interstitial lung disease and increased creatinine kinase and liver enzyme values. While antisynthetase antibodies were searched for, an empirical therapy with high-dose methylprednisolone of $200 \mathrm{mg} \cdot$ day $^{-1}$ was initiated.
Due to the development of an acute respiratory distress syndrome, mechanical ventilation commenced after intubation of the patient. A lung protective ventilation strategy, utilising pressure support of $22 \mathrm{cmH}_{2} \mathrm{O} \quad\left(1 \mathrm{cmH}_{2} \mathrm{O}=0.1 \mathrm{kPa}\right)$ and positive end-expiratory pressure of $10 \mathrm{cmH}_{2} \mathrm{O}$, was chosen. Initially, an inspiratory fraction of oxygen $\left(\mathrm{FI}_{1} \mathrm{O}_{2}\right)$ of $100 \%$ was necessary to provide sufficient oxygenation. At first, oxygenation index $\left(\mathrm{Pa}, \mathrm{O}_{2} / \mathrm{FI}_{1} \mathrm{O}_{2}\right)$ values were low, at $8-9.3 \mathrm{kPa}$. There was no clinical evidence for elevated left atrial pressure. Treatment with vibramycin and levofloxacin was started and the already installed steroid therapy was continued for 4 days with a reduction to $50 \mathrm{mg} \cdot \mathrm{day}^{-1}$ afterwards. Bronchoalveolar lavage was performed on the second day of hospitalisation. The microbiological evaluation provided no evidence for
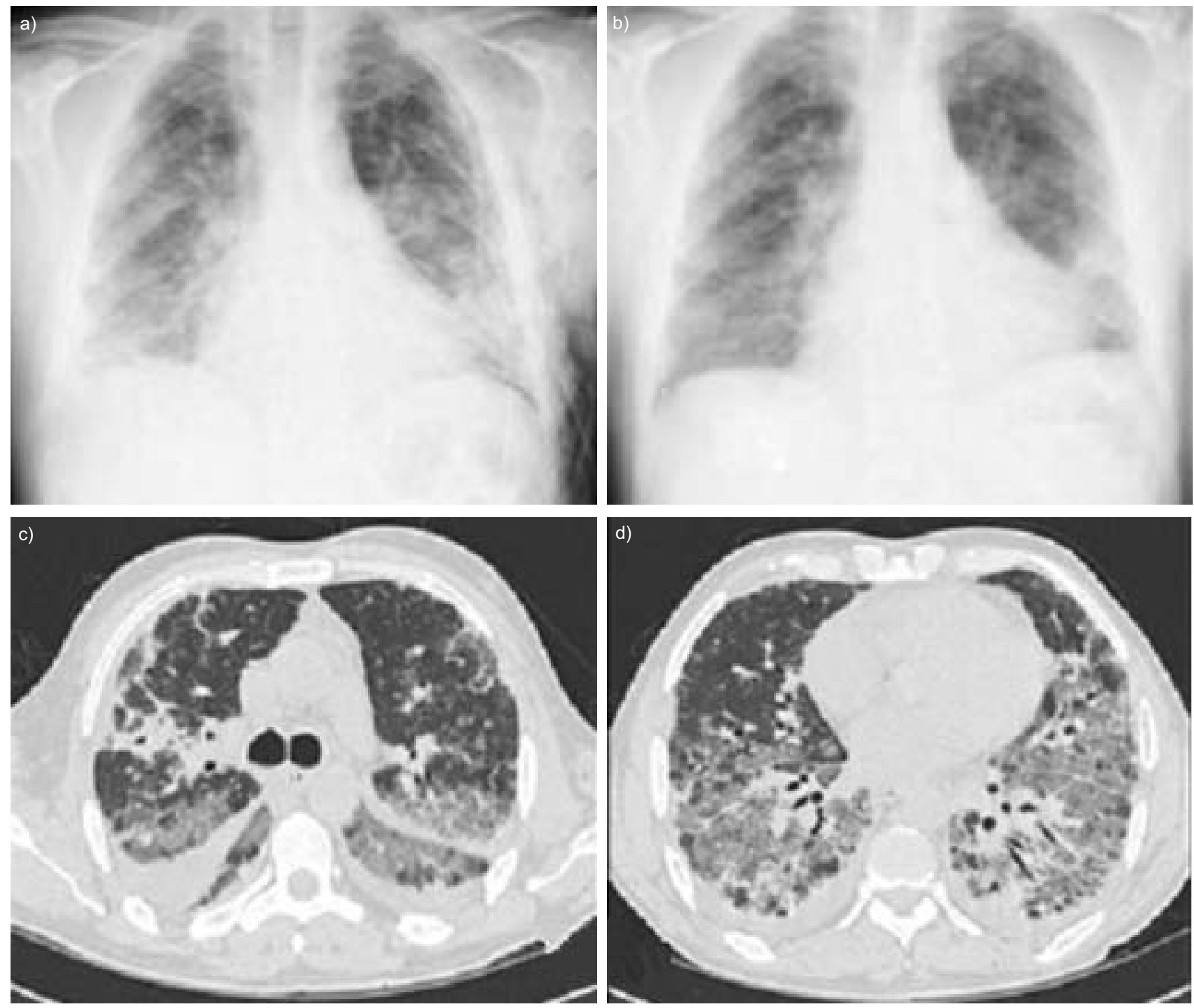

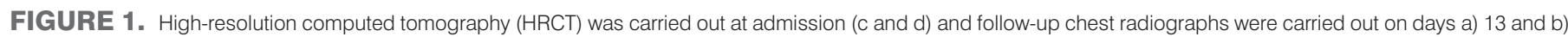

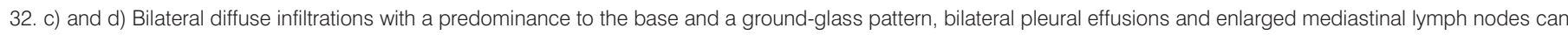

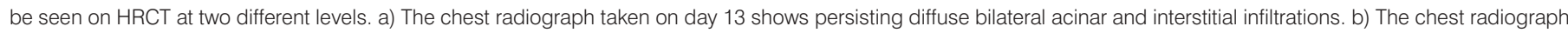
taken at the time of discharge shows distinctive resolution of the initial acinar and reticular pattern under treatment. 
bacterial, fungal or viral infection. The immunological differentiation revealed a white cell count of $0.06 \times 10^{6}$ cells $\cdot \mathrm{mL}^{-1}$, with a cellular pattern of $47.5 \%$ neutrophils, $18.5 \%$ lymphocytes and a low $\mathrm{T} 4 / \mathrm{T} 8$ lymphocyte ratio of 0.1 .

During the course of the treatment with corticosteroids, the patient was successfully weaned from the ventilator and was extubated on day 6 after admission to the intensive care unit. He was then transferred to a ward, still under high oxygen flow. The patient complained of a general weakness and disabling pains in both shoulders and muscles. Laboratory tests revealed increased antinuclear antibodies at a titre of $1: 1,280$, a synonym anti-Ro of 118 units (<20 units), an aminoacyl-transfer (t)RNA synthetase antibody (Jo-1) of 182 units (<20 units) and a rheuma factor of 39 $\left(<20 \mathrm{IU} \cdot \mathrm{mL}^{-1}\right)$. The positive titre of anti-Jo-1 supported the present diagnosis of an antisynthetase syndrome with an interstitial lung disease. To further specify the nature of the persisting diffuse pulmonary disease (fig. 1a), an open lung biopsy was performed. In the wedge resection of the left upper lobe, no granuloma, no necrosis and no eosinophily could be found. There were no signs of a vasculitis, no evidence for a tumour and no signs of bronchiolitis obliterans. The histological findings showed the appearance of a cellular nonspecific interstitial lung disease with a predominance of CD8+ Tlymphocytes (fig. 2), which is typical of this condition [4].

In order to reduce the dosage of steroids in the steroid-resistant infiltrate with hypoxaemia, and because the creatinine kinases remained elevated, a therapy with cyclosporine A was begun, as previously published $[4,6]$. As a satisfactory drug level could not be reached, the cyclosporine was replaced by tacrolimus, another calcineurin inhibitor. The dose of tacrolimus was increased to $12 \mathrm{mg}$ daily. Under this treatment, the patient's dyspnoea, $\mathrm{Pa}_{2} \mathrm{O}_{2}$ and radiological infiltration improved, as shown on the chest radiograph before discharge on day 32 of hospitalisation (fig. 1b). Figure 3 shows the whole course of the most important laboratory values, such as the creatinine kinase, lactate dehydrogenase and oxygenation indices.

The patient regained his mobility and his liver parameters were normalising. He was discharged with a treatment regimen consisting of tacrolimus with trough levels between 5-10 $\mathrm{g} \cdot \mathrm{mL}^{-1}$, associated with a low dose of prednisone. Follow-up at 6 months described a very satisfactory evolution with markedly reduced infiltrates and a dyspnoea of New York Heart Association stage I.
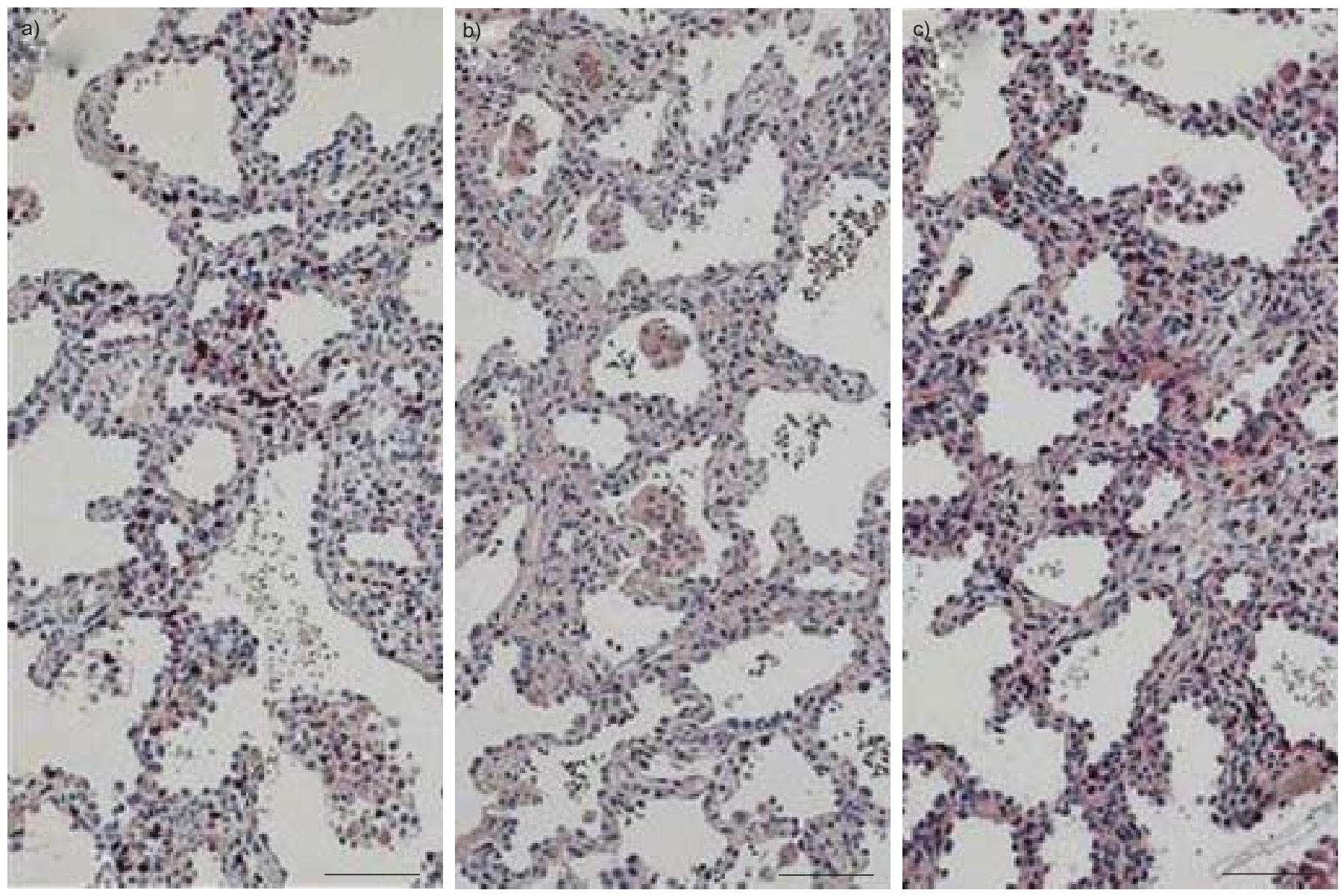

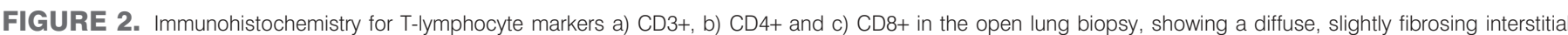

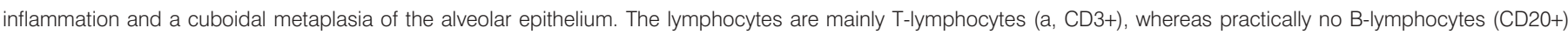

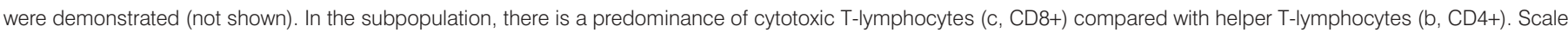
bars $=100 \mu \mathrm{m}$. 

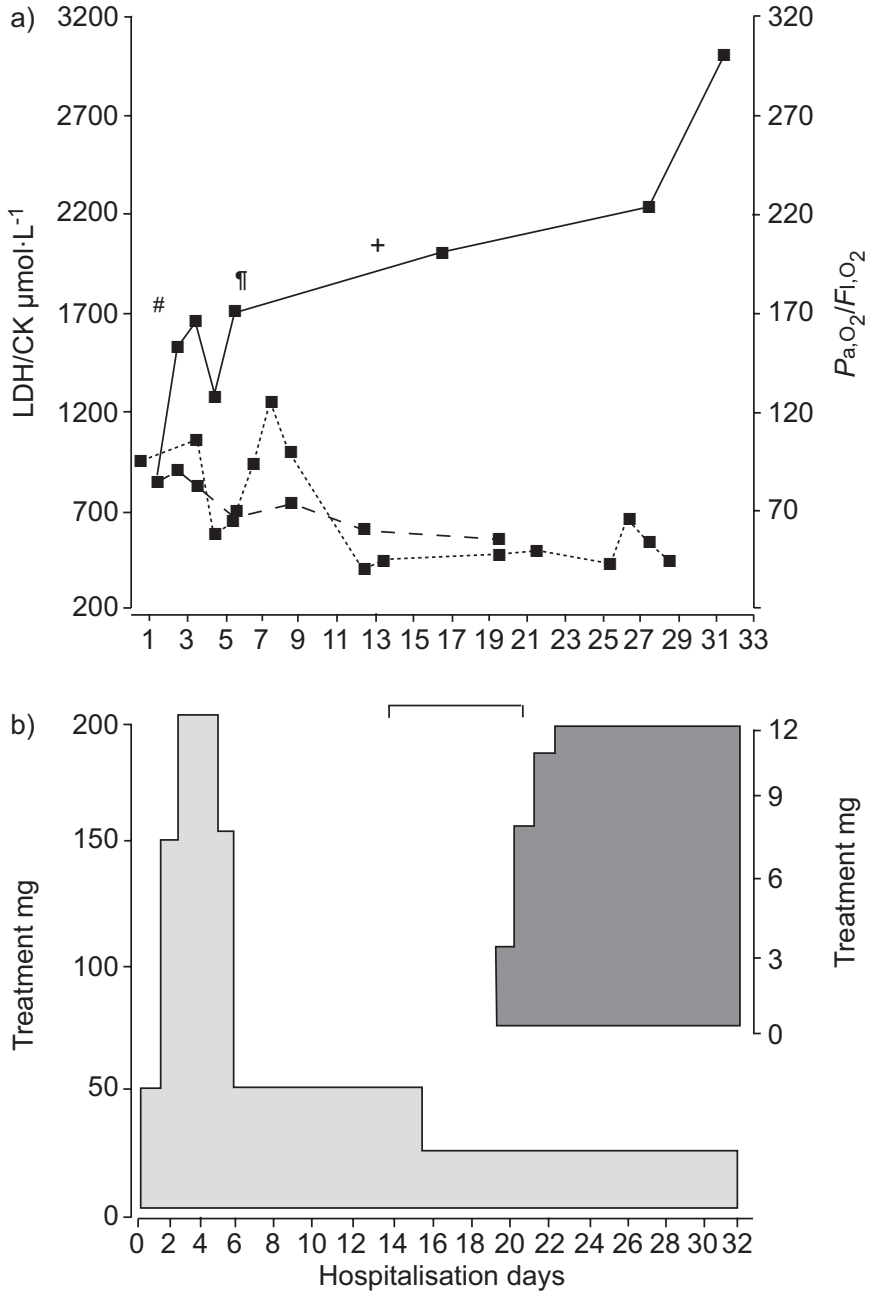

FIGURE 3. Laboratory follow-up and treatments. a) The course of laboratory values, such as creatinine kinase, lactate dehydrogenase $(\mathrm{LDH})$ and arterial oxygen tension $\left(\mathrm{Pa}_{1} \mathrm{O}_{2}\right)$ /inspiratory oxygen fraction $\left(\mathrm{Fl}_{1} \mathrm{O}_{2}\right)$ ratio in the context of b) the history of medications. The values are illustrated as an overview of the whole

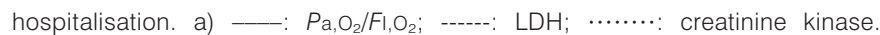
b) —_: period of cyclosporine administration; : : prednisone (maximum $200 \mathrm{mg}$ );

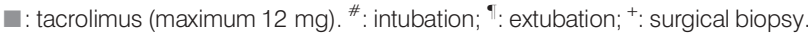

\section{DISCUSSION}

PM and DM are systemic inflammatory diseases that affect skeletal muscles and other organs, especially the lung, leading to a high morbidity in such patients. PM and DM are diagnosed according to the criteria of BOHAN and PETER [7]. These criteria include symmetrical proximal muscle weakness, either with or without dysphagia, respiratory muscle weakness, muscle enzyme elevations, electromyopathic abnormalities, compatible muscle biopsy and/or skin rash of DM.

In PM and DM, interstitial lung diseases can lead to lifethreatening complications, such as ventilatory failure, secondary pulmonary hypertension and cor pulmonale [3]. The prevalence of pulmonary involvement in PM and DM has been reported to be $46 \%$. In PM and DM, the survival rate of patients suffering from interstitial lung diseases is lower than the rate of patients without interstitial lung diseases $[3,8]$.
In patients with $\mathrm{PM}$, the musculature shows an inflammatory infiltrate, composed of CD8+ T-cells and macrophages, which destroy the myocytes by granular exocytose. AsCHERMAN [9] has recently reported a specific CD8+ T-cell proliferation in the presence of histidyl-tRNA synthetase (Jo-1), the presumed target autoantigen. Antisynthetase antibodies are directed towards enzymes that acetylate tRNAs. Another hypothesis postulates a viral infection. Several viruses, such as the picorna virus family (including coxsackie viruses), use these enzymes when they replicate inside host cells [10, 11]. During this process, viral RNA and histidyl-tRNA synthetase form a complex inside myocytes. This might result in an immune response with production of autoantibodies, which might generate the disease.

In a study performed in 1991, LOVE et al. [12] described a different prevalence of interstitial lung diseases: $89 \%$ in the group had an anti-Jo positive serology, whereas in the group without an anti-Jo serology, a prevalence of $9 \%$ could be found. HIRAKATA and NAGAI [1] described the histology of interstitial lung diseases associated with DM and PM as showing a NSIP pattern rather than a usual interstitial pneumonia pattern (UIP). In a study by COTTIN et al. [13], 11 out of 17 (65\%) patients who were evaluated by a wedge resection had a histological pattern of NSIP. Similarly, Douglas et al. [14] detected a rate of $82 \%$ of NSIP. The present patient had a similar NSIP, with a predominance of CD8 lymphocytes in the tissular immunostaining and in the bronchoalveolar lavage, as previously described $[4,15]$.

The most common findings in HRCT are irregular linear opacities with areas of consolidation and ground-lass attenuation, suggesting active inflammation, as can be seen in the cellular NSIP, which tends to evolve into fibrotic NSIP; this is difficult to differentiate radiologically and histologically from UIP, with honeycombing and lung destruction being present $[16,17]$.

For the initial treatment, steroids are often still described as the first choice of treatment [18]. Even if most patients with idiopathic inflammatory myopathy respond at least partially to corticosteroid therapies, additional immunosuppressive agents are necessary for many of them.

SAUTY et al. [4] described the good response of these interstitial lung diseases to cyclosporine in a detailed series of four cases. One year later, NAWATA et al. [5] observed an incidence of corticosteroid-resistant interstitial lung diseases in $82 \%$ of the cases in a group with low creatinine kinase levels. All cases with steroid resistance showed a positive response to cyclosporine A treatment. In a nationwide Japanese multicentre study, 53 patients were included. Similarly, they found that those patients who received a combination therapy, consisting of corticosteroids and cyclosporine A, had a better chance of survival than those who received only steroids [18]. As an alternative to cyclosporine A, tacrolimus, another calcineurin inhibitor, shows a similar mode of action. In two different reports $[19,20]$, where this new agent was used in patients with antisynthetase-associated interstitial lung diseases, there was also a significant improvement of all pulmonary parameters and of muscle strength, as well as of creatinine kinase levels, as seen with the present patient. 


\section{Conclusions}

Polymyositis and dermatomyositis can be associated with severe interstitial lung diseases, most frequently nonspecific interstitial pneumonitis. Different immunosuppressant agents are in use; the most potent in this setting seems to be cyclosporine A or tacrolimus, in combination with a low dose of corticosteroids. The present case showed the resolution of an acute respiratory distress syndrome related to a nonspecific interstitial pneumonitis, secondary to an antisynthetase syndrome under the treatment of tacrolimus, allowing the early discharge of the patient without oxygen.

\section{ACKNOWLEDGEMENTS}

The authors thank R. Holderegger for her secretarial support.

\section{REFERENCES}

1 Hirakata M, Nagai S. Interstitial lung disease in polymyositis and dermatomyositis. Curr Opin Rheumatol 2000; 12: 501-508.

2 Takiawa H, Shiga J, Moroi Y, Miyachi S, Nishiwaki M, Miyamoto T. Interstitial lung disease in dermatomyositis: clinicopathological study. J Rheumatol 1987; 14: 102-107.

3 Marie I, Hachulla E, Chérin P, et al. Interstitial lung disease in polymyositis and dermatomyositis. Arthritis Rheum 2002; 47: 614-622.

4 Sauty A, Rochat T, Schoch OD, et al. Pulmonary fibrosis with predominant CD8 lymphocytic alveolitis and anti-Jo1 antibodies. Eur Respir J 1997; 10: 2907-2912.

5 Nawata Y, Kurasawa K, Takabayashi K, et al. Corticosteroid resistant interstitial pneumonitis in dermatomyositis/polymyositis: prediction and treatment with cyclosporine. J Rheumatol 1999; 26: 1527-1533.

6 Miyake S, Ohtani Y, Sawada M, et al. Usefulness of cyclosporine $\mathrm{A}$ on rapidly progressive interstitial pneumonia in dermatomyositis. Sarcoidosis Vasc Diffuse Lung Dis 2002; 19: 128-133.

7 Bohan A, Peter JB. Polymyositis and dermatomyositis: first of two parts. N Engl J Med 1975; 292: 344-347.

8 Arsura EL, Greenberg AS. Adverse impact of interstitial pulmonary fibrosis in polymyositis and dermatomyositis. Semin Arthritis Rheum 1988; 18: 29-37.
9 Ascherman DP. The role of Jo-1 in the immunopathogenesis of polymyositis: current hypotheses. Curr Rheumatol Rep 2003; 5: 425-430.

10 Bowles NE, Dubowitz V, Sewry CA, Archard LC. Dermatomyositis, polymyositis and Coxsackie-virus infection. Lancet 1987; 1: 1004-1007.

11 Imbert-Masseau A, Hamidou M, Agard C, Grolleau JY, Chérin P. Antisynthetase-syndrome. Joint Bone Spine 2003; 70: 161-168.

12 Love LA, Leff RL, Fraser DD, et al. A new approach to the classification of idiopathic inflammatory myopathy: myositis-specific autoantibodies define useful homogeneous patient groups. Medicine (Baltimore) 1991; 70: 360-374.

13 Cottin V, Thivolet-Béjui F, Reynaud-Gaubert M, et al. Groupe d'Etudes et de Recherche sur les Maladies "Orphelines" Pulmonaires. Interstital Lung Disease in amyopathic dermatomyositis, dermatomyositis and polymyositis. Eur Respir J 2003; 22: 245-250.

14 Douglas WW, Tazelaar HD, Hartman TE, et al. Polymyositis-dermatomyositis-associated interstitial lung disease. Am J Respir Crit Care Med 2001; 164: 1182-1185.

15 Takada K, Nagasaka K, Mijasaka N. Polymyositis/dermatomyositis and interstitial lung disease: a new therapeutic approach with T-cell-specific immunosuppressants. Autoimmunitiy 2005; 38: 383-392.

16 Fathi M, Lundberg IE. Interstitial lung disease in polymyositis and dermatomyositis. Curr Opin Rheumatol 2005; 17: 701-706.

17 Bonnefoy O, Ferretti G, Calaque O, et al. Serial chest CT findings in interstitial lung disease associated with polymyositis-dermatomyositis. Eur J Radiol 2004; 49: 235-244.

18 Fujisawa T, Suda T, Nakamura Y, et al. Difference in clinical features and prognosis of interstitial lung disease between polymyositis and dermatomyositis. J Rheumatol 2005; 32: 58-64.

19 Oddis CV, Sciurba FC, Elmagd KA, Starzl TE. Tacrolimus in refractory polymyositis with interstitial lung disease. Lancet 1999; 353: 1762-1763.

20 Wilkes MR, Sereika SM, Fertig N, Lucas MR, Oddis CV. Treatment of antisynthetase-associated interstitial lung disease with tacrolimus. Arthritis Rheum 2005; 52: 2439-2446. 